Article

\title{
Development of Direct-Vibration Actuator for Bezel-Less Display Panels on Mobile Phones
}

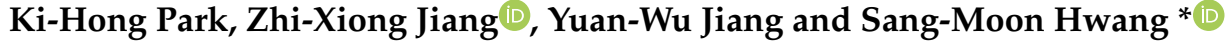 \\ School of Mechanical Engineering, Pusan National University, Busan 46241, Korea; readreamgh@gmail.com (K.-H.P.); \\ jzx20180902@gmail.com (Z.-X.J.); evan.jiang.pnu@gmail.com (Y.-W.J.) \\ * Correspondence: shwang@pusan.ac.kr; Tel.: +82-051-510-3204
}

Received: 8 May 2020; Accepted: 17 July 2020; Published: 20 July 2020

check for updates

Featured Application: The direct-vibration actuator is used in mobile devices that have bezel-less display panels. The actuator replaces the conventional dynamic receiver.

\begin{abstract}
With the development of technology, multimedia devices such as smartphones, tablets, and wearable devices have become necessities in our lives, and many new products are introduced every year. Companies are expanding smartphone displays and are developing bezel-less display panel designs. The enlarged display limits the space available for a speaker, and a new actuator must therefore be developed. Indirect-vibration actuators were developed for full-wide display designs. Using the same sound-generation principle as that of the indirect-vibration actuator, the mechanism and design of the direct-vibrating actuator is proposed in this paper. Using 3D finite element method (FEM), the force factor is obtained and used for design optimization. A sample is produced, and an experiment is conducted for sound pressure level (SPL) comparison. The experiment results show that the newly designed direct-vibration actuator can replace the dynamic receiver in mobile devices and enable the application of the bezel-less display design.
\end{abstract}

Keywords: actuator; bezel-less display; direct-vibration actuator; structure design

\section{Introduction}

Nowadays, many people use smartphones and tablets as computers to work and perform certain tasks. Along with portability, these devices provide working tools and entertainment functions simultaneously.

The dynamic receiver is a small speaker used in mobile devices to generate sounds during voice communications. It emits sounds through holes located around the display panel. The vibration and sound are two kinds of the important features for consumers while selecting smartphones. For this reason, many research studies have been conducted.

In the past, the design trend for smartphones was to make these mobile devices thinner. Thus, vibration motor and speaker was widely adopted. For tactile feedback, a horizontal vibration motor was proposed and analyzed in literature to reduce the thickness of the smartphone [1,2]. A novel structure of the vibration motor was proposed and analyzed to improve the acceleration of the conventional motor [3]. Analysis of the vibration motor using an electromagnetic and a mechanical finite element method (FEM) was introduced and verified via experiments. For the coupling analysis, nonlinear parameters including inductance and speedance was considered. The electrical, magnetic, and mechanical coupling effects 
of vibrating motor are solved by considering nonlinear parameters with FEM and numerical iteration method [4].

With regard to the small speaker used in cellular phones, Kwon et al. developed a small rectangular speaker to minimize size while retaining adequate performance [5]. To develop thinner speaker for cellular phones, Lee et al. created a novel magnetic circuit by considering the manufacturing process while minimizing the loss of acoustic performance. Instead of using vertically magnetized outer magnets, horizontally magnetized outer magnets were used to reduce the thickness [6]. A rectangular speaker with a modified structure used in liquid crystal display (LCD) phones was developed to improve sound performance. By adding new structures to the yoke, the flux density was improved [7]. Topology optimization was also used to analyze the magnetic circuit in order to improve the speaker performance in cellular phones [8].

Since the industry has progressed toward development of thinner devices, new materials are being used for speakers. To dramatically reduce device thickness, a piezoelectric speaker was developed in [9]. The piezoelectric speaker is a multilayer structure that is thinner than the dynamic receiver. However, the piezoelectric speaker is not widely used owing to its high manufacturing cost and limited performance.

Nowadays, the design trend of the smartphone is shifting toward bezel-less display. Owing to enlarged display, the available space for the dynamic receiver has decreased. The sizes of the holes for dynamic receivers have been reduced, and some parts of the display panels have been either cut or modified to allow for the dynamic receiver holes. However, the dynamic receiver holes are a hindrance to bezel-less display design. The design changes in smartphones are shown in Figure 1.

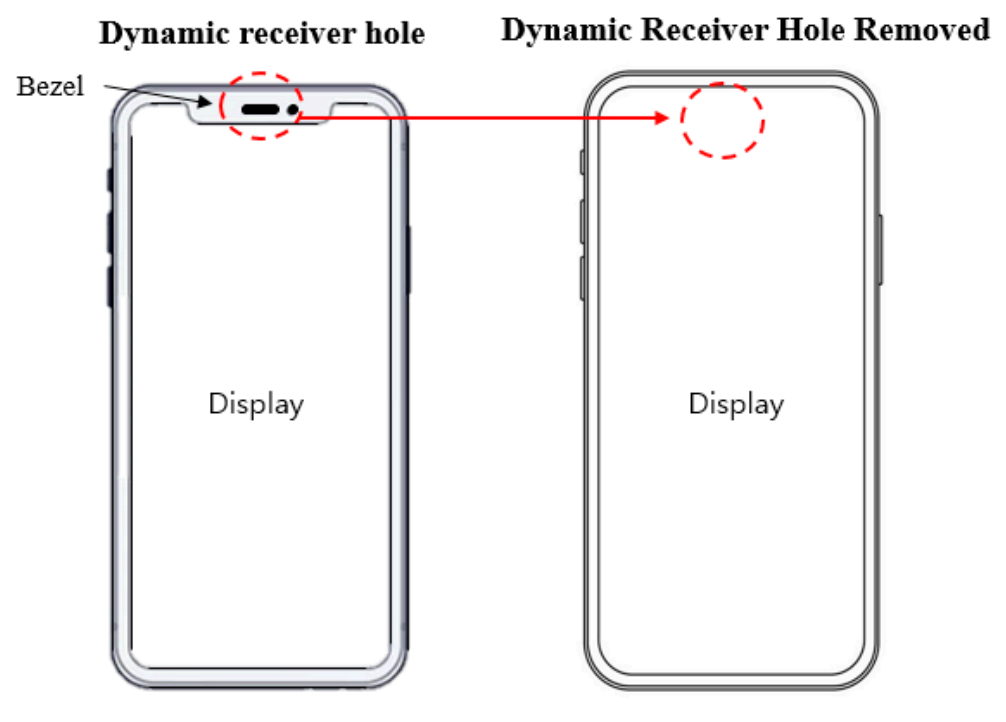

(a) Dynamic receiver at bezel

(b) Bezel-less display design

Figure 1. Design changes in smartphones.

The conventional dynamic receiver generates sound by directly vibrating a diaphragm connected to a moving coil, and the sound is transmitted to a listener through a hole located at the top of the display panel. The simplified structure of the dynamic receiver is shown in Figure 2a. 


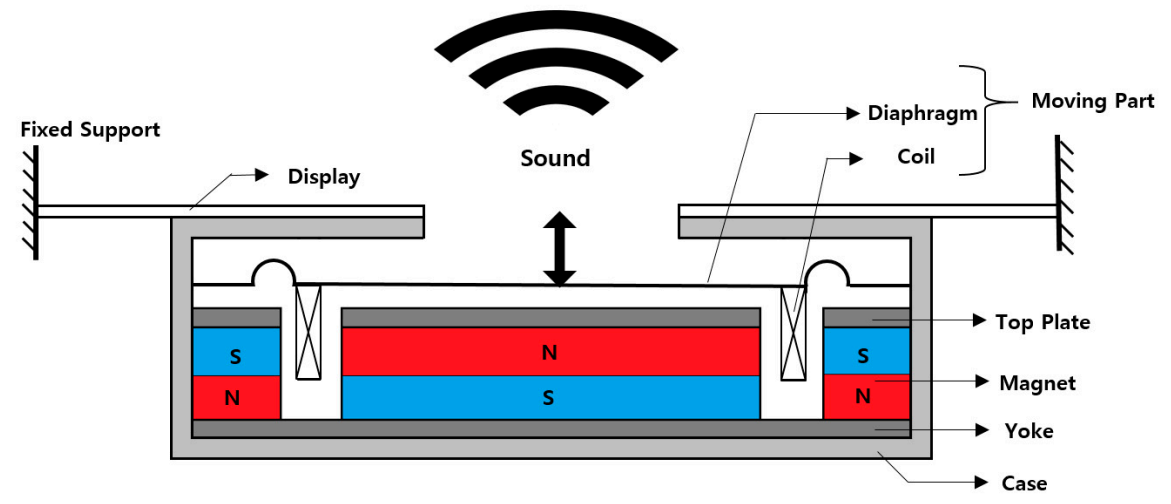

(a) Conventional dynamic receiver

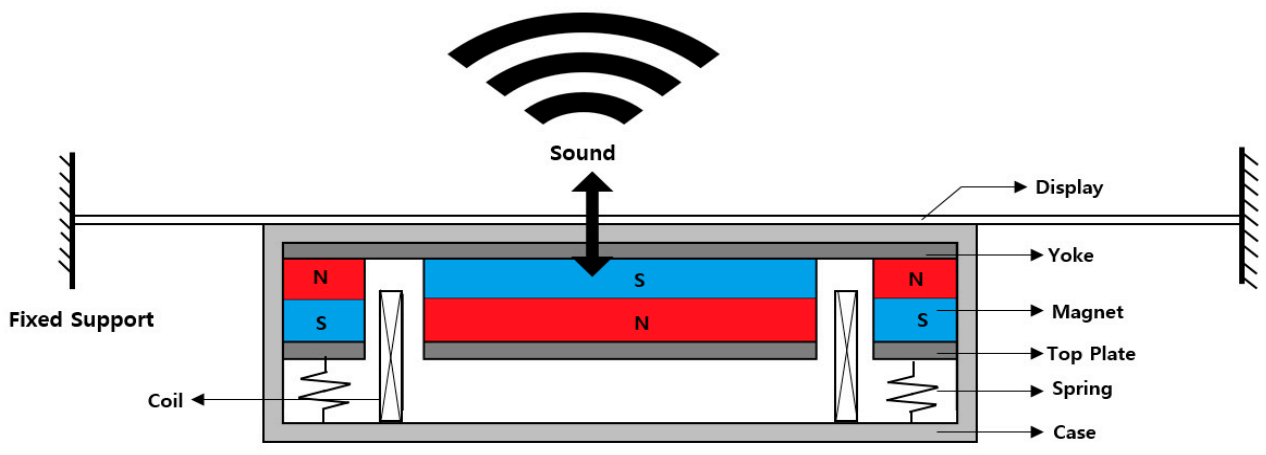

(b) Indirect-vibration actuator

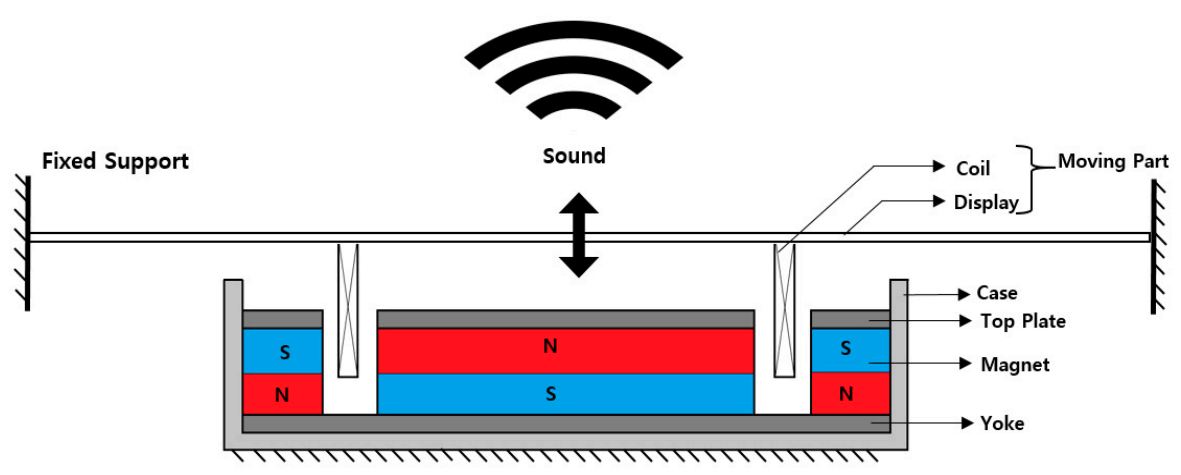

(c) Direct-vibration actuator

Figure 2. Schematics of (a) dynamic receiver, (b) indirect-vibration actuator, and (c) direct-vibration actuator.

Sound can be generated by vibrating elastic objects. In a smartphone, the vibrating display can generate sound that replaces the dynamic receiver. For a bezel-less-display smartphone, indirect-vibration actuators have been introduced and analyzed [10]. In the indirect-vibration actuator, the oscillating 
coil is located inside a case. Then, the coil vibrates the case, which transmits vibrations to display panel. The vibrating display generates the sound that the users can hear. The simplified structure of the indirect-vibration actuator and the working principle described using the mass and spring system are shown in Figures $2 \mathrm{~b}$ and $3 \mathrm{a}$, respectively.

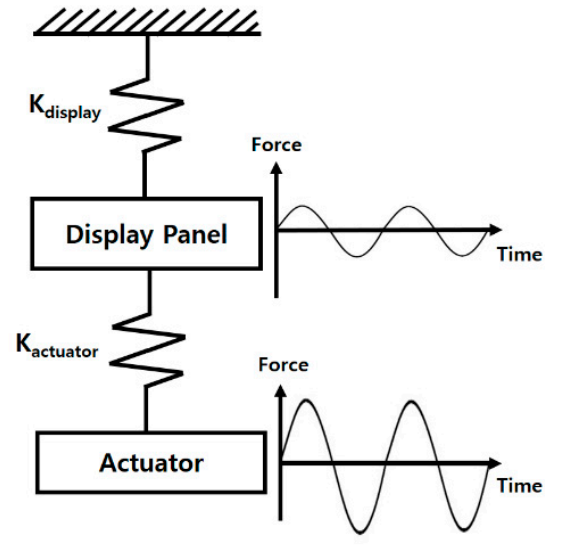

(a) Indirect-vibration actuator

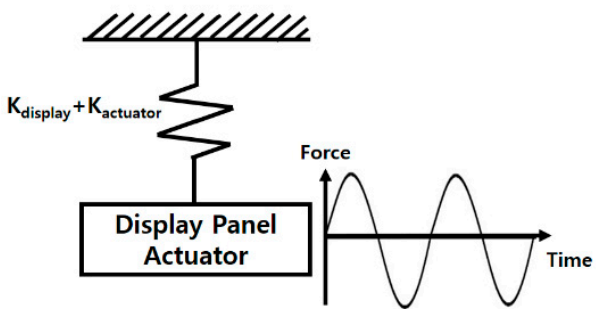

(b) Direct-vibration actuator

Figure 3. Indirect- and direct-vibration actuators described using mass and spring system.

Attaching the actuator directly to the display can also generate sound. This is called a direct-vibration actuator. Unlike the indirect-vibration actuator, the direct-vibration actuator's coil is attached directly underneath the display. The vibrating coil transmits vibrations directly to the display to generate sound. The structure of the direct-vibration actuator and the working principle described using a mass and spring system are shown in Figures 2c and 3b, respectively.

In this paper, the direct-vibration actuator is designed and analyzed. Using sensitivity analysis with force factors, the structure of the direct-vibration actuator is optimized. In the end, an optimized sample is produced, and an experiment is conducted to compare the sound pressure levels (SPLs) between the direct-vibration actuator and dynamic receiver.

Considering manufacturing assembly, the actuator components are grouped as Figure $4 \mathrm{a}$. The spring and contact pad is connected directly to the display panel. Under the spring and contact pad, the frame insert is added for the purpose of holding the entire actuator component. The Yoke ass'y consist of center top plate, magnets and yoke which forms a part of electromagnetic circuit. The voice coil is inserted between the center top late and outer top plate with suspensions. After the assembly, the moving voice coil is connected with the spring, suspension and a contact pad where it vibrates the display panel. The assembled design and cross section view is depicted in Figure $4 b, c$, respectively. Owing to limited space, the exterior dimensions are limited to $13 \times 10.0 \times 3.5 \mathrm{~mm}$. The resistance of the coil is $6 \Omega$ with an input power of $1 \mathrm{~W}$. 


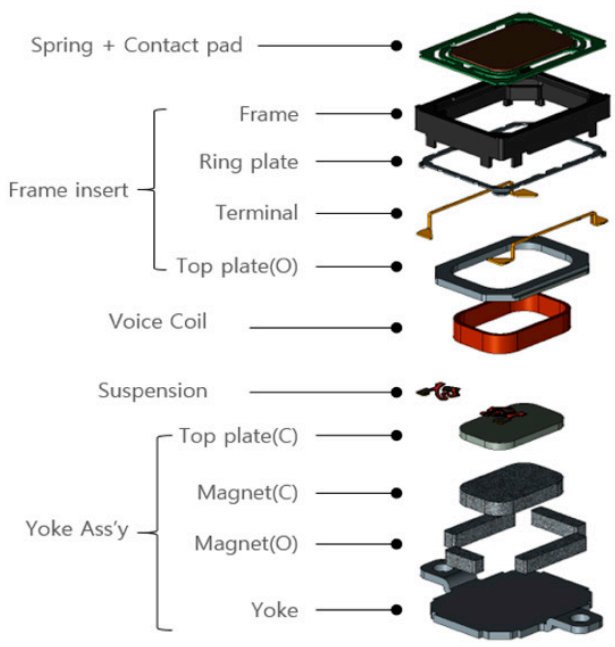

(a) Components of direct-vibration actuator

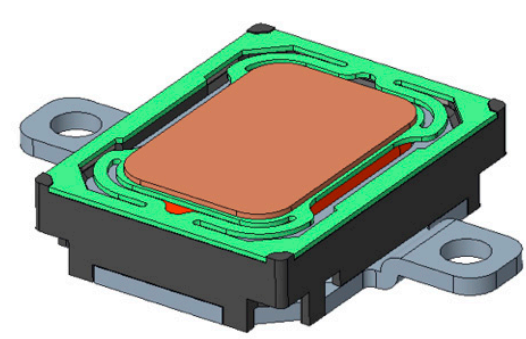

(b) Assembled design

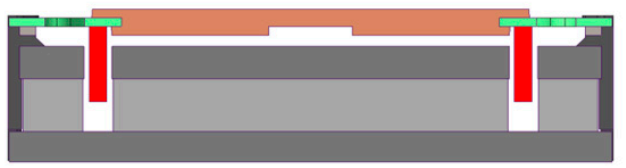

(c) Cross section

Figure 4. Structure of direct-vibration actuator.

\section{Analysis}

\subsection{Working Principle of Actuator}

The principle of the dynamic receiver and the actuator is based on Fleming's left-hand rule. Given the direction of the current flowing in the coil and the direction of the magnetic field, the law states the direction of the Lorentz force, which is the force applied to the coil. The force is applied perpendicularly to the magnetic field and to the direction of the current flowing into the coil.

The electromagnetic circuit of the actuator includes the yoke, top plate, permanent magnets, and coil. The permanent magnet is the source of the magnetic field. The magnetic flux is concentrated on the coil by the top plate and the yoke. Alternating current (AC) is fed into the coil from the power source, which makes the coil vibrate in the axial direction.

\subsection{Electromagnetic Analysis}

Using the 3D finite element method by commercial software, the flux density on the coil is obtained. The governing equation describing flux density B is expressed as

$$
\mathrm{B}=\nabla \times \mathrm{A}
$$

where B is the magnetic flux density, $\nabla \times$ is the vector curl operation, and A is the magnetic vector potential.

The magnitude of the Lorentz force in the coil can be expressed as

$$
\mathrm{F}=\oint \mathrm{Id} l \times \mathrm{B}
$$

where I is the current in the coil, and $l$ is the total coil length.

The force factor is used to present the performance of the actuator. The force factor can be calculated by dividing the Lorentz force by the current or multiplying flux density of the coil by the total coil length. This is written as

$$
\text { Force factor }=\mathrm{B} l[\mathrm{~N} / \mathrm{A}]
$$


Given the same input current, a higher force factor indicates a larger force generated in the coil. The force factor is related to the total force, acceleration, and SPL. When the force factor increases, the SPL increases.

The material properties needed in electromagnetic analysis are listed in Table 1 . The material of the top plate and yoke is Steel Plate Cold Commercial (SPCC), which has a nonlinear relationship between B and $\mathrm{H}$. The relationship between $\mathrm{B}$ and $\mathrm{H}$ can be expressed as

$$
\mathrm{B}=\mu(\mathrm{H}) \mathrm{H}
$$

where $\mathrm{H}$ is the magnetic field intensity. $\mathrm{B}$ and $\mathrm{H}$ correlate to the nonlinear value, which is called the permeability. On the B-H curve, the permeability can be obtained by calculating the slope, which varies. The B-H curve of SPCC is shown in Figure 5. The type of mesh, element size, and element number for FEM analysis are detailed in Table 2. The tetrahedral and hexahedral mesh is used depending on the shape of each structure. A finer mesh is used in the coil, and the air region is created around the actuator.

Table 1. Material properties for electromagnetic analysis.

\begin{tabular}{ccccc}
\hline Part & Material & Property & Value & Unit \\
\hline Air & - & Permeability & $4 \pi \times 10^{-7}$ & $\mathrm{H} / \mathrm{m}$ \\
Magnet(N48H) & NdFeB & Remanence & 1.4 & $\mathrm{~T}$ \\
Top Plate & SPCC & Permeability & B-H curve & $\mathrm{H} / \mathrm{m}$ \\
Yoke & SPCC & Permeability & B-H curve & $\mathrm{H} / \mathrm{m}$ \\
Coil & Copper & Permeability & $4 \pi \times 10^{-7}$ & $\mathrm{H} / \mathrm{m}$ \\
\hline
\end{tabular}

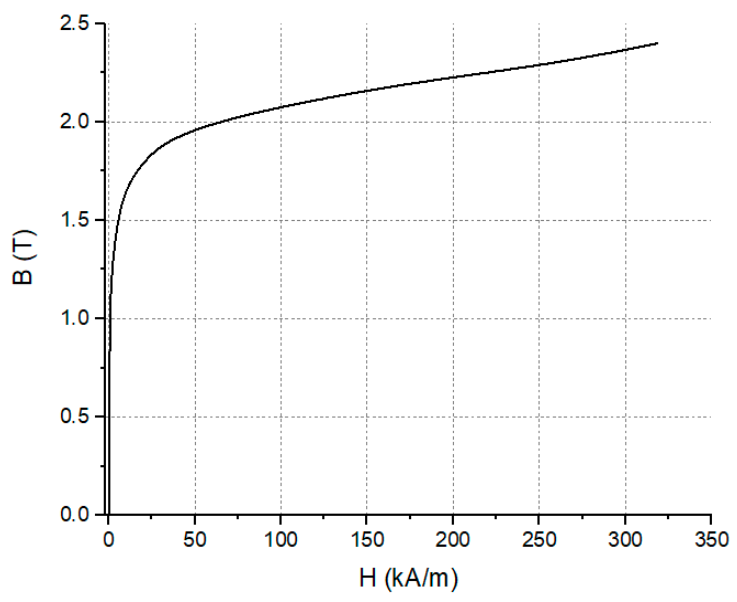

Figure 5. B-H curve of SPCC.

Table 2. Mesh and element used in FEM analysis.

\begin{tabular}{cccc}
\hline Part & Element Type & Element Size & Element Number \\
\hline Air & Tetrahedral & $2.5 \mathrm{~mm}$ & $2.77 \times 10^{5}$ \\
Magnet & Hexahedral & $1.0 \mathrm{~mm}$ & $2.27 \times 10^{5}$ \\
Top Plate & Tetrahedral & $0.5 \mathrm{~mm}$ & $1.94 \times 10^{5}$ \\
Yoke & Tetrahedral & $0.5 \mathrm{~mm}$ & $2.58 \times 10^{5}$ \\
Coil & Hexahedral & $0.2 \mathrm{~mm}$ & $1.66 \times 10^{6}$ \\
\hline
\end{tabular}




\section{Design Optimization}

Since there are many components under the display, the direct-vibration actuator needs to have a maximum electromagnetic force under a limited geometry constraint. The geometry constraint is the maximum size of the actuator. The limited size is $13.0 \times 10.0 \times 3.5 \mathrm{~mm}$, and the goal is to find the maximum force factor by changing the dimensions of the top plate, yoke, permanent magnet, and coil in the given space. The variations of the flux density and force factor are analyzed by changing two design variables using a sensitivity analysis:

1. The variation of the force factor on the actuator when changing the thickness of the actuator's yoke, top plate, and permanent magnet

2. The variation of the force factor when changing the diameter and number of coil layers.

The effect of current on the force factor is very small due to the small current flow in the coil. The current affects about $0.13 \%$ in force factor compared to the result without the current. For this reason, the force factor is calculated without considering the current.

\subsection{Thickness Optimization}

The thicknesses of the top plate, yoke, and permanent magnets directly affect the force factor. The total thickness, including the top plate, yoke, and permanent magnet, should be $2.6 \mathrm{~mm}$. The thickness of each component is briefly shown in Figure 6.

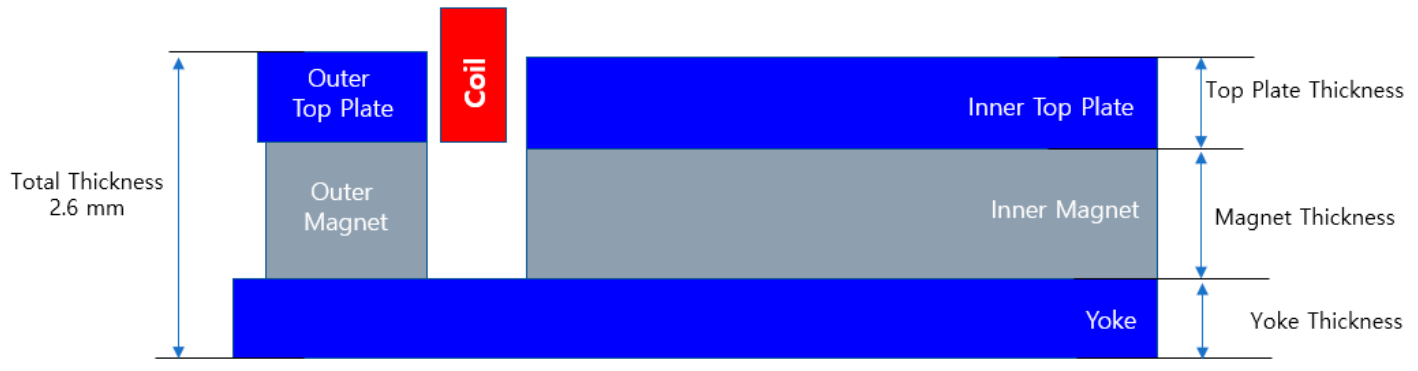

Figure 6. Thickness of components.

Increasing the permanent magnet size will strengthen the magnetic field but will decrease the top plate and yoke thickness. A decreased top plate and yoke thickness will cause magnetic flux saturation and thus less magnetic flux to pass through the coil. Consequently, the force factor decreases. Increasing the top plate and yoke thickness will decrease the size of the permanent magnets, which also leads to a decrease in the flux density and force factor.

The thickness of each component is changed to find out the maximum force factor. Table 3 shows seven cases for sensitivity analysis and the results when the coil is at a neutral position $(0 \mathrm{~mm})$. Considering the limited total height which is $2.6 \mathrm{~mm}$, the changes more than $0.2 \mathrm{~mm}$ result in poor force factor. Thus, the optimization is conducted by changing thickness by $0.2 \mathrm{~mm}$.

In optimizing the thickness, the changing thickness from $-0.2 \mathrm{~mm}$ to $0.2 \mathrm{~mm}$ shows that the thickness of the yoke greatly affects the force factor. Increasing the size of the magnets lowers the force factor, which means that magnetic flux saturation occurs at the yoke. The magnetic flux flow on Case 5 and Case 3 at the actuator cross section is depicted in Figure 7. From Figure 7, the decreased yoke thickness, Case 3, is causing magnetic flux saturation. The force factor in Case 4 varies more than in Case 5 depending on the coil position. The force factor should be consistent in every position. Thus, Case 5 is chosen owing to the higher force factor at every coil position than in the original prototype. The force factor result in every coil position is shown in Figure 8. 
Table 3. Seven cases for thickness optimization.

\begin{tabular}{cccccc}
\hline Case & $\begin{array}{c}\text { Top Plate } \\
\text { Thickness }\end{array}$ & Magnet Thickness & $\begin{array}{c}\text { Yoke } \\
\text { Thickness }\end{array}$ & $\begin{array}{c}\text { Total } \\
\text { Thickness }\end{array}$ & $\begin{array}{c}\text { Force Factor } \\
\text { (0-mm Position) }\end{array}$ \\
\hline Original & 0.75 & 1.15 & 0.70 & 2.60 & 1.259 \\
Case 1 & $0.95(+0.2)$ & $0.95(-0.2)$ & 0.70 & 2.60 & 1.222 \\
Case 2 & $0.55(-0.2)$ & $1.35(+0.2)$ & 0.70 & 2.60 & 1.235 \\
Case 3 & $0.95(+0.2)$ & 1.15 & $0.50(-0.20)$ & 2.60 & 1.171 \\
Case 4 & $0.55(-0.2)$ & 1.15 & $0.90(+0.20)$ & 2.60 & 1.261 \\
Case 5 & 0.75 & $0.95(-0.2)$ & $0.90(+0.20)$ & 2.60 & 1.263 \\
Case 6 & 0.75 & $1.35(+0.2)$ & $0.50(-0.20)$ & 2.60 & 1.210 \\
\hline
\end{tabular}

Unit: $\mathrm{mm}$.

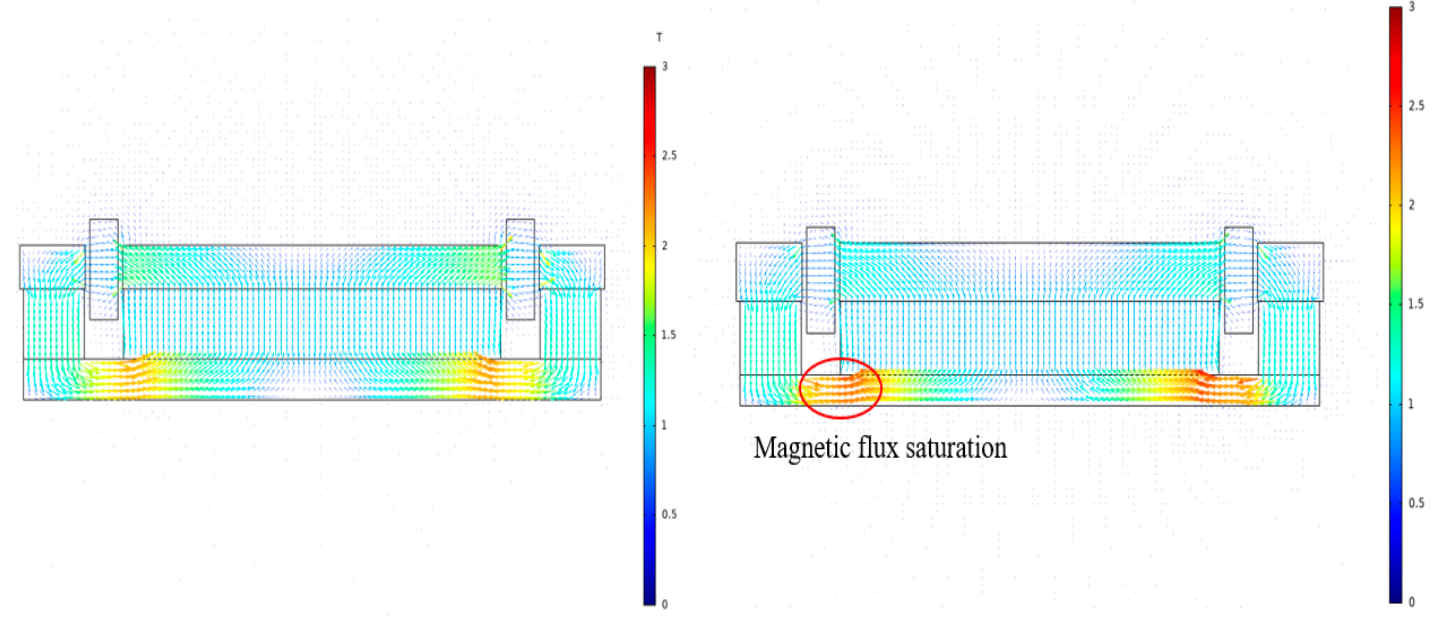

(a) Case 5

(b) Case 3 .

Figure 7. Magnetic flux density at actuator cross section.

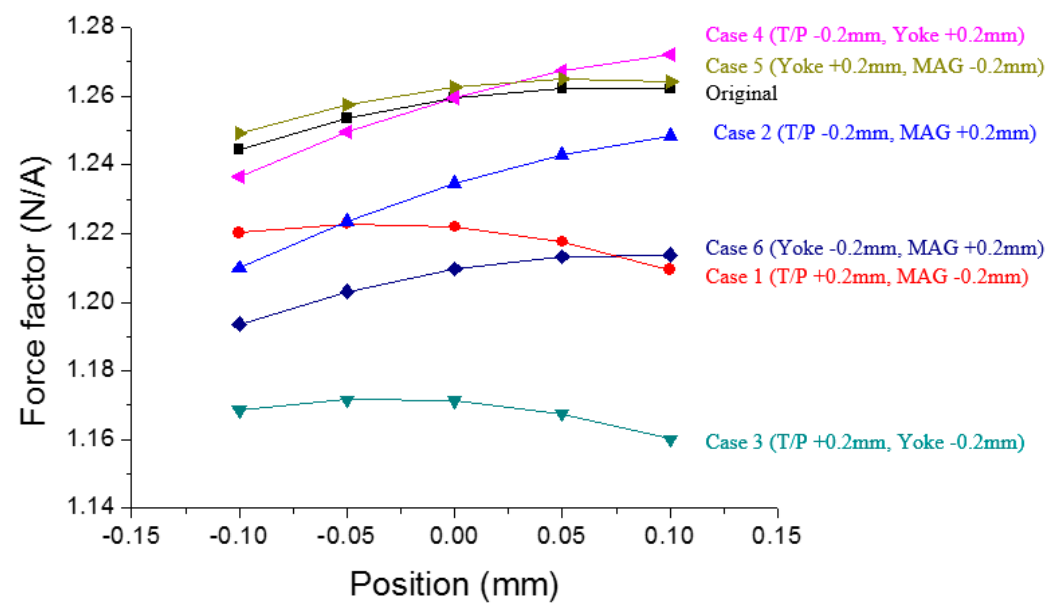

Figure 8. Thickness optimization results for seven cases. 


\subsection{Coil Optimization}

The variation in the force factor caused by the change of layers and the diameter of the coil is analyzed. The coil resistance is fixed at $6 \Omega$. The layer is the number of coil windings for each width. The diameter of the coil refers to the diameter of copper wire through which the current flows, excluding the insulation layer thickness.

While maintaining the same resistance and layer, decreasing the diameter can decrease the force factor since the resistance per unit length increases, which leads to a decrease in the total coil height. The decreased coil height may cause less magnetic flux to pass through the coil. Similarly, while maintaining the same resistance and diameter, increasing the number of layers decreases the coil height and may decrease the force factor.

With regard to the geometry constraint in the coil optimization, the distance from the yoke to the top of the coil is maintained at $3.1 \mathrm{~mm}$ when the top of the coil is in a fixed position. The exterior coil surface must be positioned at $6.25 \mathrm{~mm}$ (longitudinally) and $3.25 \mathrm{~mm}$ (laterally), respectively, from the center of the top plate.

The distance from the coil bottom to the yoke should be at least $0.15 \mathrm{~mm}$. The air gap between the coil and the top plate is fixed at $0.08 \mathrm{~mm}$. While maintaining the coil resistance at $6 \Omega$, a diameter from $0.05 \mathrm{~mm}$ to $0.15 \mathrm{~mm}$ is used, and 4, 6, 8, and 10 layers are chosen to determine the maximum force factor. The reason for choosing an even-numbered layer is that from the manufacturing process, the input wire and output wire should start and end in the same position. To maximize the force factor, it is important to find the best combination between the diameter and the total coil length. The constraints and descriptions for coil optimization are briefly shown in Figure 9.

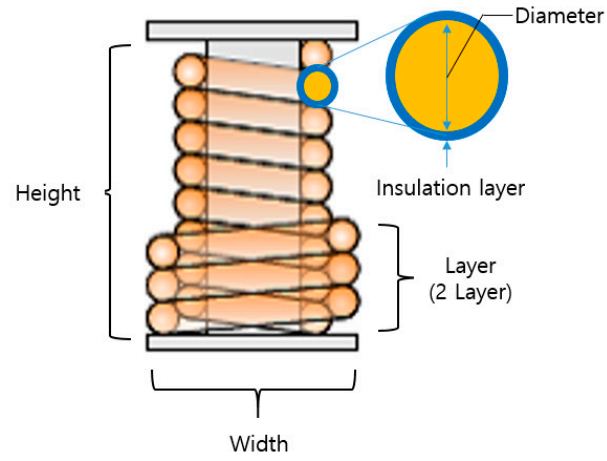

(a) Layer and diameter in coil

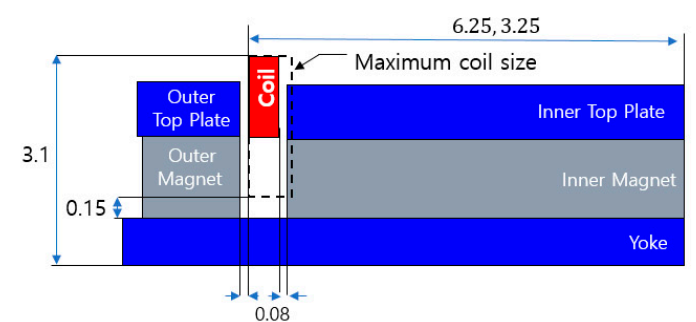

(b) Constraints in coil optimization

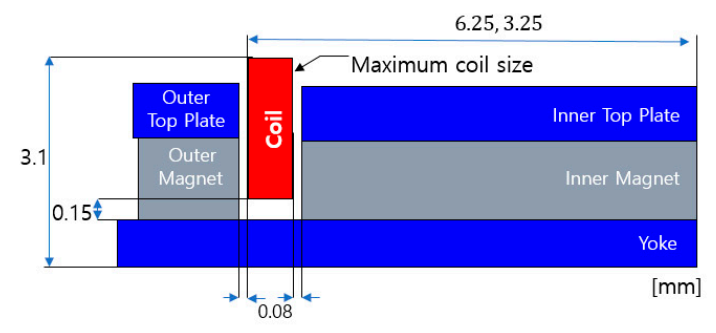

(c) Constraints in coil optimization (maximum coil size)

Figure 9. Description of coil optimization.

Table 4 lists the specifications of four cases that have the maximum force factor on the dedicated coil diameter.

The eight-layer coil with a diameter of $0.11 \mathrm{~mm}$ is found to have the maximum force factor. The maximum force factor in 4, 6, 8, 10 layers in a neutral position is shown in Figure 10.

By combining all results, the final optimized force factor is obtained, which is shown in Figure 11. The optimized model has a $12 \%$ higher force factor than the original prototype. 
Table 4. Four cases for coil optimization.

\begin{tabular}{cccccc}
\hline Case & Layer & $\begin{array}{c}\text { DCR } \\
{[\boldsymbol{\Omega}]}\end{array}$ & $\begin{array}{c}\text { Diameter } \\
{[\mathbf{m m}]}\end{array}$ & $\begin{array}{c}\text { Total Length } \\
{[\mathbf{m m}]}\end{array}$ & $\begin{array}{c}\text { Force Factor } \\
\text { (0-mm Position) }\end{array}$ \\
\hline Case 1 & 4 & 6 & 0.087 & 2096.06 & 1.264 \\
Case 2 & 6 & 6 & 0.099 & 2688.37 & 1.367 \\
Case 3 & 8 & 6 & 0.110 & 3368.81 & 1.419 \\
Case 4 & 10 & 6 & 0.118 & 3807.80 & 1.370 \\
\hline
\end{tabular}

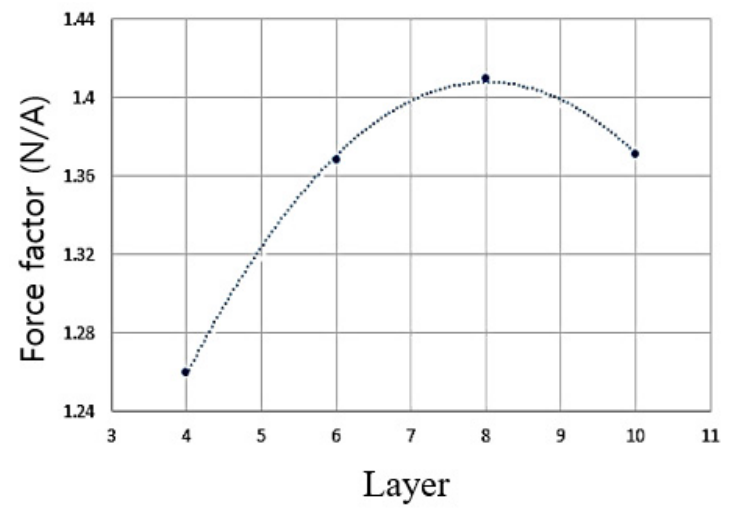

Figure 10. Optimization result for thickness and coil.

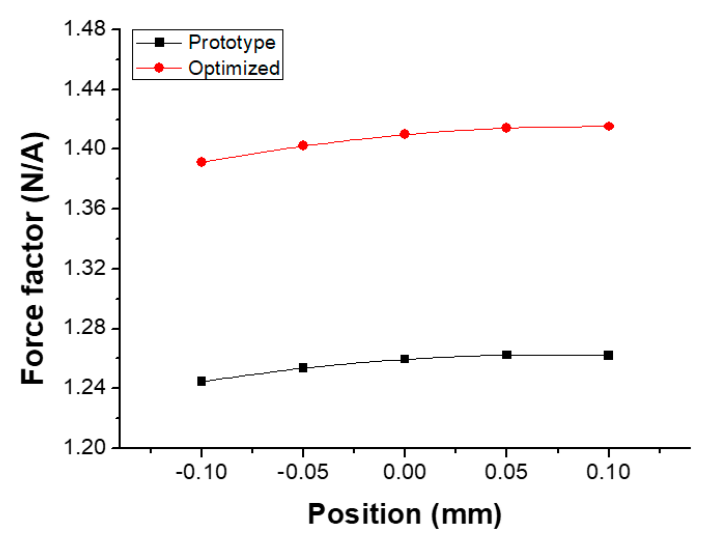

Figure 11. Force factor comparison between prototype and optimized actuator.

\section{Experiment}

After the optimization, a direct-vibration actuator sample was manufactured, as shown in Figure 12.

The experiment system (B\&K system) for measuring SPL consists of a power amplifier (B\&K, 2718, Nærum, Danmark), a microphone (B\&K, 4191) and a Pulse-Multi Analyzer (B\&K, 3560C). In the B\&K system, the accepted sound signal from the microphone is transformed into an SPL curve in the frequency domain by a Fast Fourier Transform (FFT). The experiment is conducted in an anechoic chamber, and the testing distance is selected as $0.05 \mathrm{~m}$ in the central axis direction from a microphone. The actuator is attached directly behind the LCD display panel and electric cable is connected to the actuator for the input signal. As input, a sinusoidal signal ranging from $100 \mathrm{~Hz}$ to $5000 \mathrm{~Hz}$ is used with an input power of $1 \mathrm{~W}$. Figure 13 shows the experiment setups and system connections. 


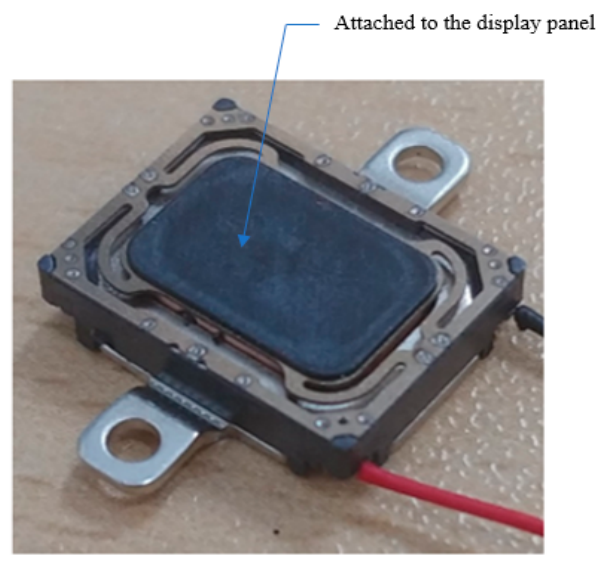

Figure 12. Manufactured sample.

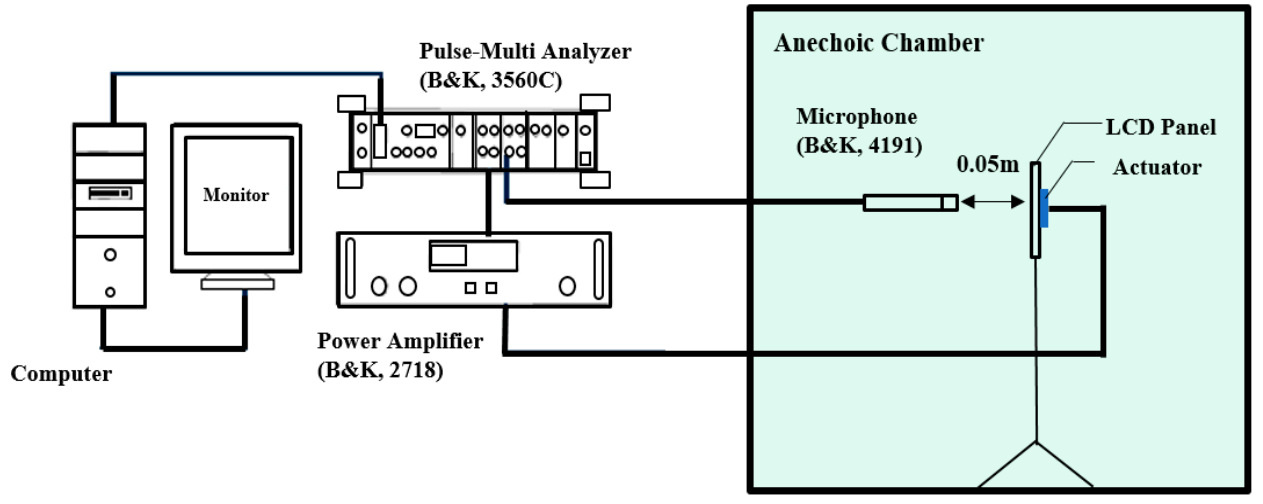

(a) Schematic of B\&K setup

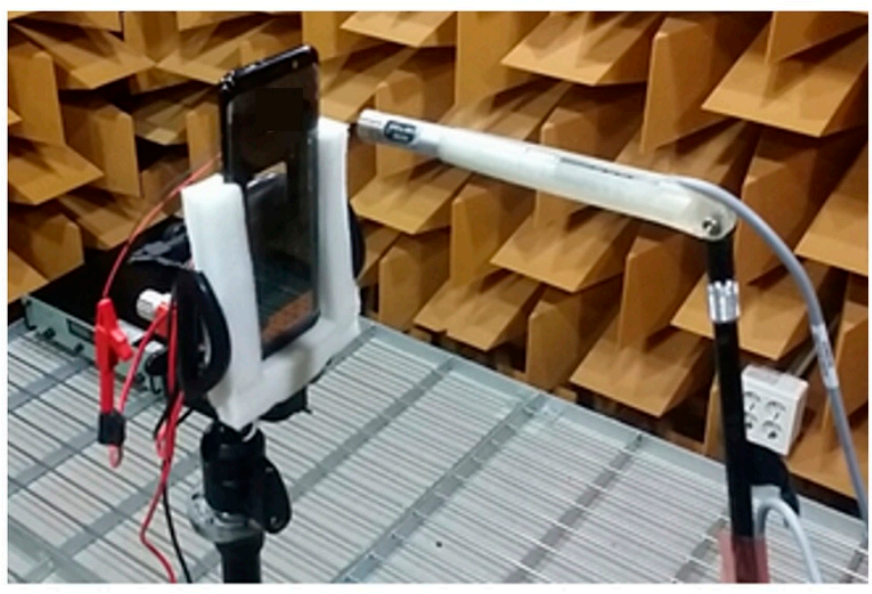

(b) Experiment setup

Figure 13. B\&K equipment and experiment setup.

The result is shown in Figure 14. The result indicates that the direct-vibration actuator can be used to replace the dynamic receiver. This enables a full-wide bezel-less display design. 


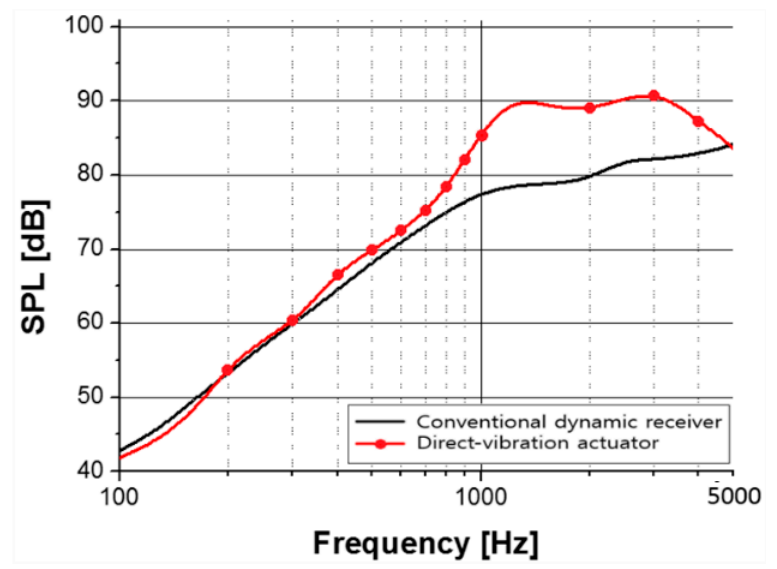

Figure 14. SPL comparison between dynamic receiver and direct-vibration actuator.

\section{Conclusions}

Smartphones have become the core technology for many industries. The main design trend is to maximize the display size while maintaining portability. To achieve the bezel-less display design, a new actuator to replace the conventional dynamic receiver is needed. The indirect-vibration actuator was developed for a bezel-less display design to generate sound by vibrating the entire display. Instead of using an indirect-vibration actuator, this paper suggests a new structure that generates sound by vibrating the display panel directly. The new structure is called the direct-vibration actuator.

By calculating the force factor via the 3D finite element method, the design was optimized. First, the thickness of the magnetic circuit component was analyzed to maximize the force factor. Then, the coil was optimized. As an optimization result, the force factor increased by about $12 \%$ compared to the original actuator. A sample was manufactured, and the SPL was compared to the dynamic receiver. The experiment result showed that the direct-vibration actuator can substitute for the dynamic receiver. This allows for bezel-less display designs on mobile devices.

Author Contributions: Conceptualization, K.-H.P., Z.-X.J., and S.-M.H.; Methodology, K.-H.P.; Software, K.-H.P. and Z.-X.J.; Validation, K.-H.P. and Z.-X.J.; Investigation, K.-H.P., Z.-X.J., and Y.-W.J.; Writing-original draft preparation, K.-H.P.; Writing—review and editing, K.-H.P., Z.-X.J., and S.-M.H.; Visualization, K.-H.P. and Y.-W.J.; Supervision, S.-M.H.; Project administration, S.-M.H. All authors have read and agreed to the published version of the manuscript.

Funding: This research received no external funding.

Conflicts of Interest: The authors declare no conflict of interest.

\section{References}

1. Lee, K.B.; Kim, J.H.; Kim, J.H. 1108. Horizontal linear vibrating actuator to reduce smartphone thickness. J. Vibroeng. 2013, 15, 2003-2011.

2. Pyo, D.; Yang, T.H.; Ryu, S.; Kwon, D.S. Novel linear impact-resonant actuator for mobile applications. Sens. Actuators Phys. 2015, 233, 460-471. [CrossRef]

3. Park, J.H.; Sun, P.; Kwon, J.H.; Hwang, S.M. Optimal design of linear vibrators used in touch screen mobile phones. J. Mech. Sci. Technol. 2013, 27, 313-318. [CrossRef]

4. Kim, J.H.; Jiang, Y.W.; Hwang, S.M. Analysis of a vibrating motor considering electrical, magnetic, and mechanical coupling effect. Appl. Sci. 2019, 9, 1434. [CrossRef]

5. Kwon, J.H.; Hwang, S.M.; Kim, K.S. Development of slim rectangular microspeaker used for minimultimedia phones. IEEE Trans. Magn. 2016, 43, 2704-2706. [CrossRef] 
6. Lee, C.M.; Kown, J.H.; Hwang, G.Y.; Hwang, S.M. Development of a new magnetic circuit for slim microspeakers. J. Appl. Phys. 2009, 105, 07E710. [CrossRef]

7. Lee, C.M.; Hwang, S.M. Development of advanced rectangular microspeakers used for wide liquid-crystal display mobile phones. J. Appl. Phys. 2011, 109, 07E504. [CrossRef]

8. Kim, W.; Kim, Y.Y. Magnetic circuit design by topology optimization for Lorentz force maximization in a microspeaker. J. Mech. Sci. Tech. 2008, 22, 1699-1706. [CrossRef]

9. Kim, H.J.; Koo, K.; Lee, S.Q.; Park, K.H.; Kim, J. High Performance Piezoelectric Microspeakers and Thin Speaker Array System. ETRI. J. 2009, 31, 680-687. [CrossRef]

10. Kim, J.H.; Jiang, Y.W.; Hwang, S.M. Analysis and Design of New Actuator Used for Full-Wide Screen LCD. Appl. Sci. 2019, 9, 4599. [CrossRef]

(C) 2020 by the authors. Licensee MDPI, Basel, Switzerland. This article is an open access article distributed under the terms and conditions of the Creative Commons Attribution (CC BY) license (http://creativecommons.org/licenses/by/4.0/). 